GRAZIELA GALLI

\title{
DIREITO AO DESENVOLVIMENTO: CONTRIBUIÇÃO DA FENOMENOLOGIA JURÍDICA
}

\author{
Dissertação de Mestrado apresentada ao \\ Departamento de Filosofia e Teoria Geral do Direito \\ da Faculdade de Direito da Universidade de São \\ Paulo para obtenção de título de Mestre em Filosofia \\ do Direito, sob orientação da Professora \\ Doutora Jeannette Antonios Maman
}

UNIVERSIDADE DE SÃO PAULO

FACULDADE DE DIREITO

SÃO PAULO 
Ao Denis. 
Agradeço à minha família pela educação e pelas oportunidades;

à Professora Doutora Jeannette Antonios Maman por toda a atenção e compreensão que me foram dedicadas; aos amigos pelo incentivo. 


\section{SUMÁRIO}

LISTA DE ABREVIATURAS

RESUMO

ABSTRACT

INTRODUÇÃO. .11

CAPÍTULO I. DIREITO AO DESENVOLVIMENTO - UMA NOÇÃO POSSÍVEL

1.1 O tema do desenvolvimento - breve introdução. .17

1.2 Evolução da abordagem do desenvolvimento. .20

1.2.1 Desenvolvimento e sustentabilidade. 22

1.2.1.1 Desenvolvimento sustentável segundo o Clube de Roma e a proposta da Fundação Bariloche. .26

1.2.2 Aspectos do subdesenvolvimento. .32

1.3 Desenvolvimento criticado a partir da filosofia do ser. .33

1.4 A experiência histórica do direito ao desenvolvimento. .36

1.5 Incorporação de diplomas internacionais ao ordenamento jurídico interno. .47

1.6 Direito ao desenvolvimento na Constituição Federal. .52

1.7 Índices de desenvolvimento .53 
1.7.3 O IOH e a sustentabilidade.

1.8 Introdução a uma abordagem fenomênica do direito ao desenvolvimento. 59

\section{CAPÍTULO II. FENOMENOLOGIA E DIREITO}

2.1 Fenomenologia existencial como modo de abordagem do direito 60

2.2 Estrutura constitutiva do Dasein .70

2.2.1 O direito inautêntico (solicitude, indulgência, indiferença, descaso e o se). .70

2.2.2 Descaso e indiferença (modo deficiente da assistência) .71

2.2.2.1 Sujeição - fenômeno econômico como assistência deficiente, voltado à compreensão do mundo.

2.2.3 A essência da verdade. .76

2.2.4 Existencial e existenciário .78

2.2.5 Direito como processo: temporal e histórico .79

2.2.6 Fenomenologia e estrutura de compreensão. .82

2.2.7 Duas atividades do conhecimento: a razão demonstrativa e o numenon. .84

2.3 Fenomenologia como caminho para se compreender o direito ao desenvolvimento.....85 
2.3.2 A compreensão do fenômeno jurídico em contraposição ao direito como mera técnica

2.4 Filosofia e pensar. 90

2.5 Direito como técnica e como fenômeno. .92

\section{CAPÍTULO III. DESENVOLVIMENTO E FILOSOFIA DO SER}

3.1 Via fenomenológica. .94

3.2 Direito como cuidado e direito como ocupação. .95

\section{CAPÍTULO IV. FILOSOFIA DO SER COMO CAMINHO DO DESENVOLVIMENTO}

4.1 Um novo modo de se pensar o direito ao desenvolvimento.

4.2 Desenvolvimento para além do bem-estar. 103

CAPÍTULO V. DIREITO AO DESENVOLVIMENTO COMO PROTEÇÃO DO SERHUMANO

5.1 O direito ao desenvolvimento como direito-do-ser-humano 106

5.2 Evolução histórica da proteção jurídica do ser-humano. .108

5.2.1 A ONU. 
5.4. O sentido do direito ao desenvolvimento (justiça, modo de ser do ser jurídico autêntico)

5.5. Liberdade, igualdade e solidariedade.

CONCLUSÃO

BIBLIOGRAFIA... 


\section{LISTA DE ABREVIATURAS}

BIRD: Banco Internacional para a Reconstrução e o Desenvolvimento

ENDS 2015: Estratégia Nacional de Desenvolvimento Sustentável 2015

EUA: Estados Unidos da América

FMI: Fundo Monetário Internacional

IBGE: Instituto Brasileiro de Geografia Estatística

IDH: Índice de Desenvolvimento Humano

IDH-M: Índice de Desenvolvimento Humano Municipal

IOH: Índice de Oportunidade Humana

IPEA: Instituto de Pesquisa Econômica Aplicada

OEA: Organização dos Estados Americanos

OIT: Organização Internacional do Trabalho

OMC: Organização Mundial do Comércio

ONU: Organização das Nações Unidas

OUA: Organização da Unidade Africana

PIB: Produto Interno Bruto

PIDCP: Pacto Internacional sobre Direitos Civis e Políticos

PNUD: Programa das Nações Unidas para o Desenvolvimento 


\section{RESUMO}

Este trabalho trata do direito ao desenvolvimento como direito-do-ser-humano pela via da fenomenologia existencial. E, para um pensamento crítico do fenômeno do desenvolvimento mundial, a preocupação recai sobre a questão da sustentabilidade no sentido de um re-pensar da condição da existência humana como modo de existir planetário. 


\begin{abstract}
This work deals with the right to development as a right-of-human-being by means of existential phenomenology. And to think critically about the phenomenon of global development, the concern lies with the issue of sustainability to re-think the condition of human existence as a way of planetary existence.
\end{abstract}

